\title{
Microscale strain partitioning? Differential quartz crystallographic fabric development in Phyllite, Hindu Kush, Northwestern Pakistan
}

\author{
K. P. Larson ${ }^{1}$, J. L. Lamming ${ }^{2,1}$, and S. Faisal ${ }^{1}$ \\ ${ }^{1}$ Earth and Environmental Sciences, University of British Columbia, Okanagan, 3247 University Way, \\ Kelowna, BC V1V 1V7, Canada \\ ${ }^{2}$ Department of Geological Sciences, University of Saskatchewan, 114 Science Place, Saskatoon, \\ SK S7N 5E2, Canada
}

Correspondence to: K. P. Larson (kyle.larson@ubc.ca)

Received: 12 August 2014 - Published in Solid Earth Discuss.: 3 September 2014

Revised: 10 November 2014 - Accepted: 19 November 2014 - Published: 16 December 2014

\begin{abstract}
Spatially referenced quartz $c$ axis fabrics demonstrate the preservation of multiple, distinct fabrics in a specimen collected from northwestern Pakistan. The overall fabric yielded by the specimen is dominated by a single population of quartz grains, while the fabric signatures of two other unique, spatially distinct populations are overwhelmed. It is these minor fabrics, however, that provide information on temperature of deformation $\left(403 \pm 50^{\circ} \mathrm{C}\right)$, differential stress $(8.6+2.6 /-1.5 \mathrm{MPa}$ to $15.0+3.8 /-2.5 \mathrm{MPa})$, strain rate $\left(10^{-16} \mathrm{~s}^{-1}\right.$ to $\left.10^{-15} \mathrm{~s}^{-1}\right)$, and strain partitioning recorded by the specimen.
\end{abstract}

\section{Introduction}

Crystallographic analysis has been long employed to study the strain histories recorded by rock forming minerals (e.g. Turner, 1942; Sander, 1950; Bouchez and Pêcher, 1976; Zhang and Karato, 1995). While investigation of crystallographic fabrics have been successfully carried out on a wide variety of mineral phases, quartz has been one of the most common targets to elucidate strain within continental crust due to its near ubiquity in such rocks. The development of crystallographic fabrics in quartz has been actively investigated (e.g. Lister and Williams, 1979; Schmid and Casey, 1986) and utilized in studies of geologic material (e.g. Bouchez and Pêcher, 1976; Blumenfeld et al., 1986; Law et al., 1990, 2004, 2011, 2013; Xypolias and Koukouvelas, 2001; Larson and Cottle, 2014) during the past 5 decades. While advances in our understanding and implications of the fabrics have advanced, so too have the methods available to extract lattice orientation data. Universal stages are still employed to generate quartz $c$ axis crystallographic fabrics (e.g. Kile, 2009); however, more technical methods such as x-ray goniometry (e.g. Wenk, 1985) and electron backscattered diffraction (EBSD) (e.g. Prior et al., 1999) can potentially provide a higher density of information and orientation data for secondary axes. In addition, techniques utilizing EBSD and automated optical fabric analysers (e.g. Heilbronner and Pauli, 1993; Feuten and Goodchild, 2001; Wilson et al., 2003, 2007; Pajdzik and Glazer, 2006) have the advantage of producing spatially referenced data with the ability to automatically generate achsenverteilungsanalyse (AVA or axial distribution diagrams) (e.g. Sander, 1950). Such a diagram, essentially a map of crystallographic orientation within the specimen analysed, can help facilitate the investigation and comparison of spatially distinct grains, groups of grains, or zones within a specimen. Spatially referenced crystallographic fabrics also allow for the investigation of strain recorded in grains of various sizes, the potential effects of matrix phases, and the spatial positioning of grains adjacent to local features such as porphyroclasts.

One significant application of spatially referenced crystallographic fabric data is to examine within-specimen fabric orientation heterogeneities. This type of analysis has been employed to distinguish between preferred orientations in new, recrystallized grains vs. relict porphyroclasts (e.g. Law et al., 2010) and to identify variable dissolution in quartz veins (Wilson et al., 2009). Such studies highlight the potentially significant differences in crystallographic fabric 


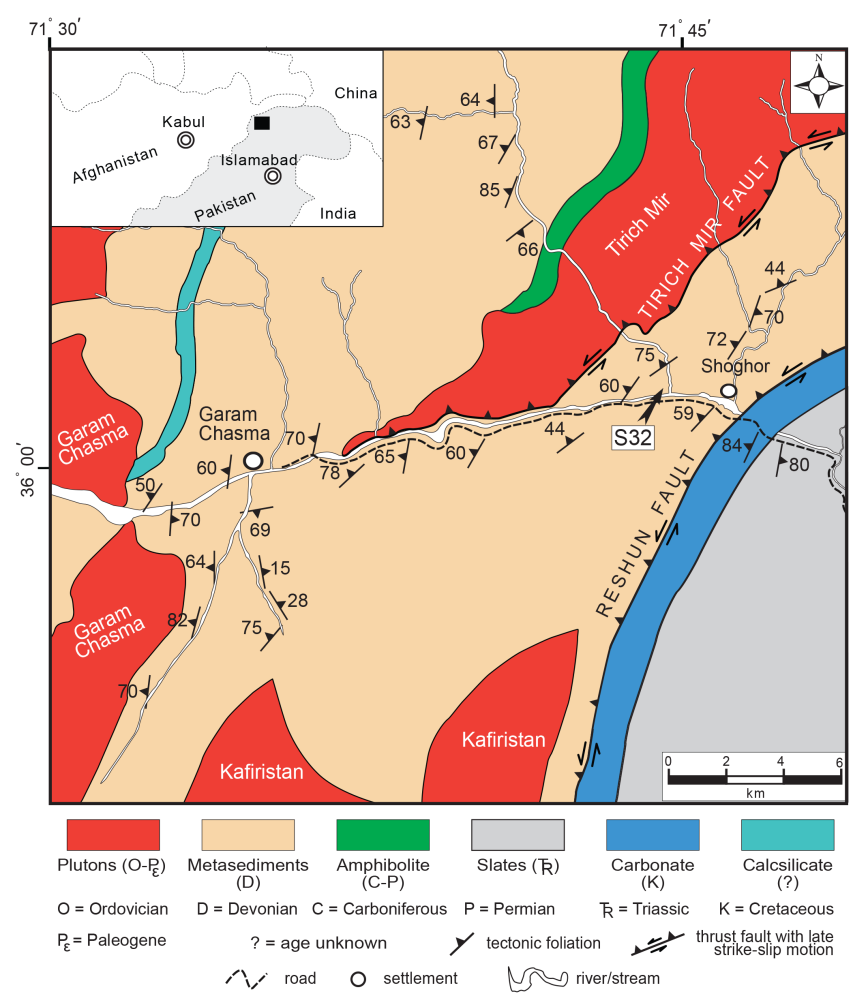

Figure 1. General geology map of the Garam Chasma/Chitral region, NW Pakistan (after Faisal et al., 2014). Specimen collection location is indicated. Field area location is shown in regional scale inset map.

development for distinct grain populations and/or spatially separated areas of a single specimen.

This study presents new, spatially referenced crystallographic fabric data from a specimen collected in the Chitral region of northwestern Pakistan. This specimen records three distinct quartz crystallographic fabrics that could be related to differences in spatial position, recrystallized grain size, and interaction with matrix phases in the specimen. The existence of different crystallographic fabrics that could be related to significant changes in the texture and/or mineralogy of spatially restricted areas of a specimen may provide insight into strain partitioning at the microstructural scale. Moreover, the existence of distinct crystallographic fabrics at the thin section scale has implications for the representation of strain for a specimen using a single fabric and potentially for assessing relative differences between spatially separated specimens.

\section{Geological setting}

The Chitral region is located within the eastern Hindu Kush of northwestern Pakistan (Fig. 1). The geology of the area is dominated by Paleozoic protoliths, mainly low-grade metasedimentary rocks that locally reach sillimanite grade
(Gaetani et al., 1996; Zanchi et al., 2000; Hildebrand et al., 2001; Zanchi and Gaetani, 2011; Faisal et al., 2014). These metasedimentary rocks are intruded by a series of plutonic bodies that range in age from Paleozoic (Kafiris$\tan -483 \pm 21 \mathrm{Ma}$; Debon et al., 1987), through Mesozoic (Tirich Mir - 114 to 121 Ma, Desio, 1964; Hildebrand et al., 2000; Heuberger et al., 2007), to Cenozoic (Garam Chasma - $24 \mathrm{Ma}$; Hildebrand et al., 1998). The region records a protracted deformational history with the earliest records indicating Late Triassic deformation and metamorphism and recent events culminating in the Early Miocene (Faisal et al., 2014).

Specimen S32, the subject of the present study, is part of a suite of quartz-rich specimens collected in the Chitral region. It is a quartz + muscovite + chlorite phyllite (Fig. 2a, b) collected between the Tirich Mir and Reshun faults (Fig. 1). The foliation in the specimen is defined by planar muscovite and chlorite laths while the lineation is defined by a grain-shape fabric of the same minerals. A thin section of specimen S32 was cut parallel to the macroscopic lineation $\left(25^{\circ} \rightarrow 006^{\circ}\right)$ and perpendicular to the foliation $\left(330^{\circ} / 38^{\circ} \mathrm{NE}\right)$. The specimen has a heterogeneous mineral distribution with localized quartz-rich lenses (Fig. 2a, b) that have a bimodal grain-size distribution (Fig. 2d). The coarser grain population within the lens has a median area (as calculated for an ellipse using the long and short axes of each grain) in this section of $161 \mu \mathrm{m}^{2}$ with a standard deviation of $45 \mu \mathrm{m}^{2}$ and an aspect ratio of 2.5 (standard deviation of 1.0). The smaller grain-size population within the quartz-rich lens is characterized by a median area of $81 \mu \mathrm{m}^{2}$ with a standard deviation of $20 \mu \mathrm{m}^{2}$ and an aspect ratio of 2.3 (standard deviation of 1.0). The long axes of both grain-size populations are typically at low angles relative to the dominant foliation. The quartz-rich lenses are surrounded by phyllosilicate-rich layers that contain quartz grains with a median elliptical equivalent surface area of $52 \mu \mathrm{m}^{2}$ with a standard deviation of $13 \mu \mathrm{m}^{2}$ and an aspect ratio of 2.0 (standard deviation of 0.7 ). These grains are typically elongate parallel to the foliation direction. The crystallographic fabrics of each quartz grain population are investigated below.

\section{Method}

The specimen was oriented during collection and cut parallel to macroscopic lineation and perpendicular to the macroscopic foliation. The orientations of $c$ axes within the specimen were determined using a G50 Automated Fabric Analyser (e.g. Wilson and Peternell, 2011) with an RGB filtered, colour charge-coupled device (CCD) sensor and white LEDs at an optical resolution of $10 \mu \mathrm{m}$. Previous research has shown that $c$ axis orientations determined using an automated fabric analyser like the G50 are indistinguishable from those determined using X-ray (Wilson et al., 2007) and EBSD methods (Peternell et al., 2010). The G50 outputs an interactive AVA diagram (Fig. 2c), or $c$ axis map, of the thin 

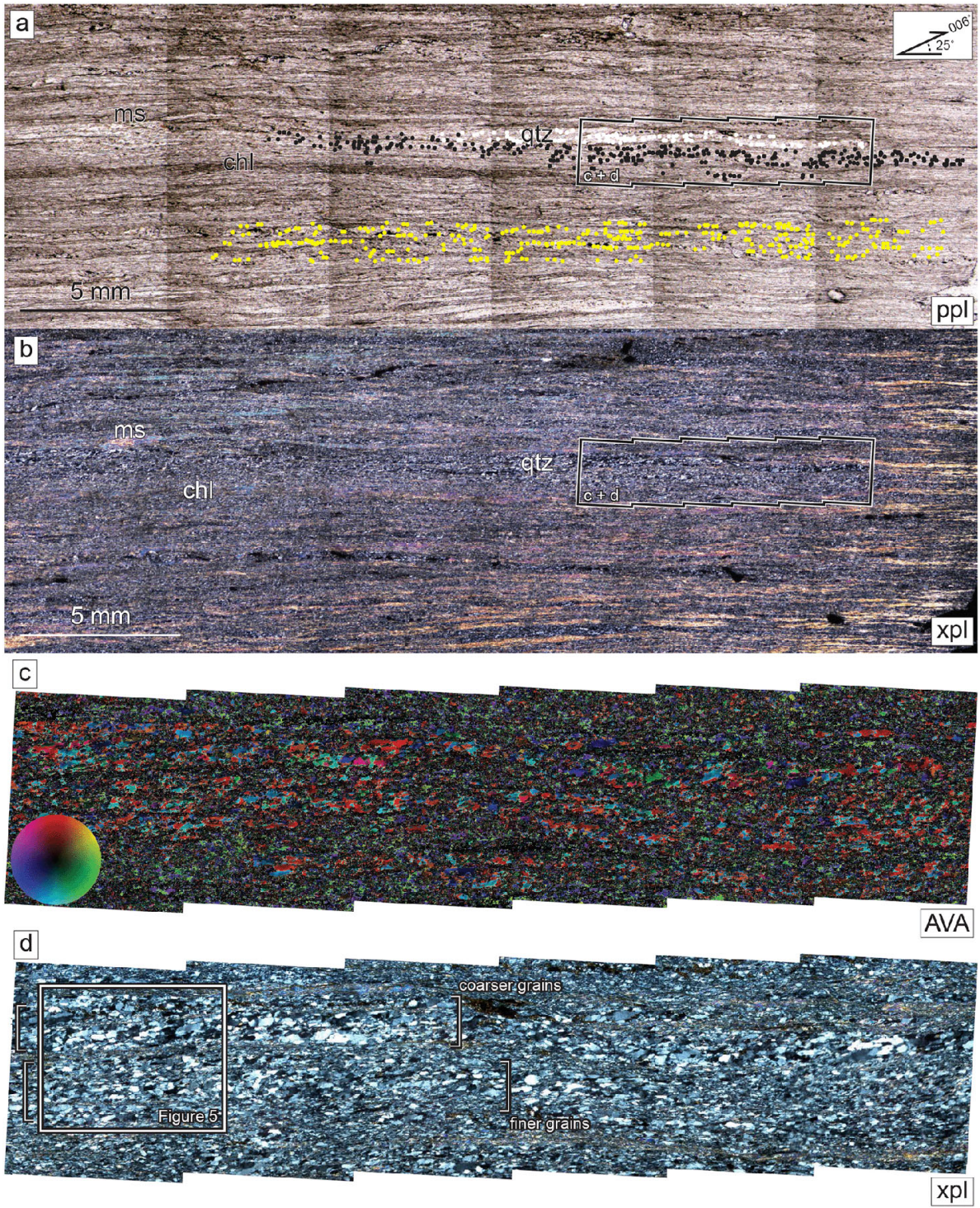

Figure 2. Thin section scale photomicrographs of specimen S32 presented in plane-polarized light (a), cross-polarized light (b), and as an AVA diagram (c). The location of quartz grains analysed is indicated by different coloured and shaded circles in (c). White circles denote a coarser grain within the quartz-rich lens; black circles indicate a finer grain within a quartz-rich lens; yellow circles mark a matrix quartz grain measured. A more detailed cross-polarized photomicrograph of the quartz-rich lens is shown in (d); coarser and finer populations are marked.

section that was used to build crystallographic fabrics. Because each pixel of the AVA diagram has unique $c$ axis orientation data associated with it, the crystallographic fabrics of spatially distinct sections within the specimens can be investigated by picking the exact locations within grains from which the orientation data are to be extracted.

The existence of three spatially and texturally distinct quartz grain-size populations within the specimen allows the direct investigation of potential microscale quartz crystallographic fabric and strain differences. Such investigations allow assessment of the sense of shear recorded by the different populations and the slip systems active during fabric for- mation. Moreover, the different grain-size populations lend themselves to paleopiezometric investigation through the application of the Stipp and Tullis (2003) paleopiezometer as modified by Holyoke and Kronenberg (2010). These paleopiezometric estimates, in turn, can be combined with derived deformation temperatures to estimate strain rates. The results from this study have bearing on microscale strain, stress, and strain rate partitioning during deformation and on the potential homogenizing effects of dominant grain-size populations in crystallographic fabric data, which may obscure contributions from other smaller populations. 


\section{Quartz microstructures}

In the equal area stereonets used to present the $c$ axis data, the lineation lies horizontally across the equator, while the foliation is a vertical plane cutting through the equator. The stereonets are oriented such that a dextral asymmetry indicates top-to-the-east-southeast shear.

\subsection{Quartz microstructures}

The quartz grains that comprise the finer and coarser populations within the quartz-rich lens in the specimen demonstrate textural characteristics consistent with dynamic recrystallization. In both populations there is evidence of minor bulging (Fig. 3a), subgrain development (Fig. 3b, c), and deformation lamellae (Fig. 3b, c). These textures are most consistent with Regime 2 crystallization of Hirth and Tullis (1992) or the SGR (subgrain rotation recrystallization) category of Stipp et al. (2002).

In contrast, strong evidence for dynamic recrystallization was not observed in the quartz grains found within the phyllitic matrix outside of the quartz-rich lens. Here, the grains are commonly partially surrounded by muscovite and/or chlorite laths (Fig. 3d) and as such typically have restricted contact with one another.

\subsection{Quartz crystallographic fabric results}

When examined in bulk (i.e. looking at fabric automatically generated from a non-discriminant sampling grid) specimen S32 yields a crystallographic fabric consistent $\langle a\rangle$, prism $\langle a\rangle$, and prism $[c]$ slip systems (Schmid and Casey, 1986; Fig. 4a). There is a slight asymmetry in the basal $\langle a\rangle$ fabric that is consistent with top-to-the-east-southeast shear. If the crystallographic fabrics of the three differently sized quartz grain populations are examined individually, however, it becomes apparent that the overall or bulk crystallographic fabric is dominated by the matrix quartz population.

The crystallographic fabric yielded from the matrix quartz bears a strong resemblance to the bulk fabric (Fig. 4b). While showing similar activation of the prism $\langle a\rangle$ and prism $[c]$ slip systems, the matrix quartz $c$ axis fabric indicates preferred activation of the rhomb $\langle a\rangle$ slip system over basal $\langle a\rangle$. Moreover, in the hand-picked pattern there appears to be a stronger prism $\langle a\rangle$ component and a more well-defined rhomb $\langle a\rangle$ asymmetry (top to the east-southeast). The prism $[c]$ positions also appear to define an asymmetry, but it yields the opposite shear sense to that indicated by the basal $\langle a\rangle$ fabric (Fig. 4b).

In contrast to both the bulk and the matrix grain-size population, the fabric yielded by the finer-size population within the quartz lens comprises a single girdle with activation of the prism $\langle a\rangle$ and rhomb $\langle a\rangle$ slip systems (Fig. 4c). There is no indication of prism $[c]$ activation. The single girdle is
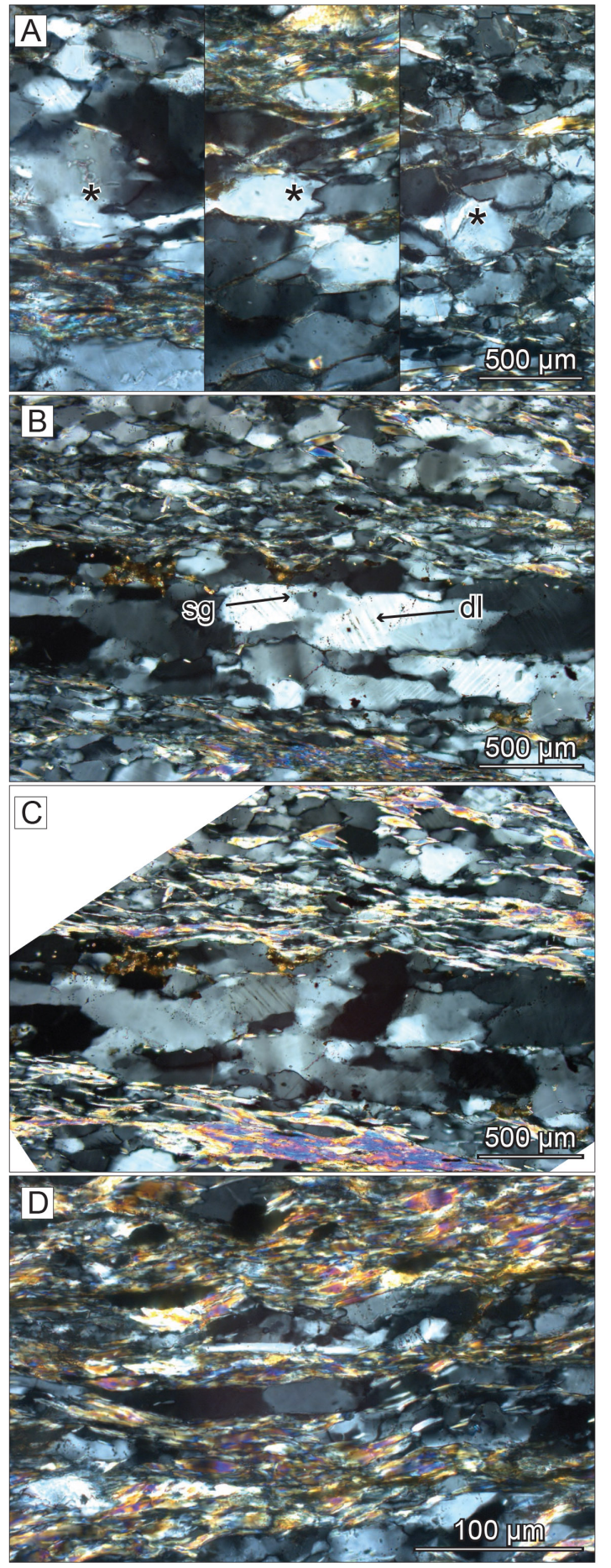

Figure 3. Quartz microtextures observed in thin sections. All photomicrographs are cross polarized light. (a) Three examples of minor bulging recrystallization. (b) Subgrain development within the quartz-rich lens. Also visible are deformation lamellae. (c) Same location as in (b) with the stage rotated to further highlight subgrain formation. (d) A matrix quartz grain (centre) encased by phyllosilicates. 

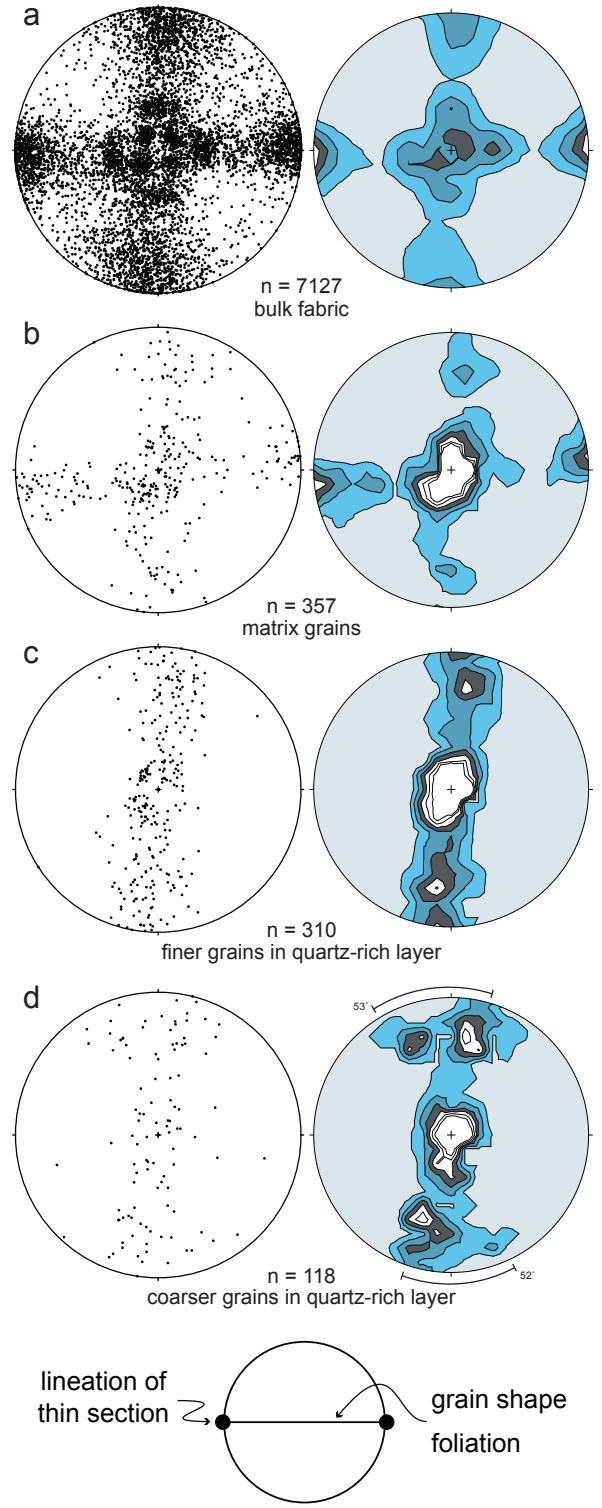

Thin section was cut along a line equivalent to a lineation of $25^{\circ} \rightarrow 006^{\circ}$

Figure 4. Quartz crystallographic fabrics from various quartz populations in the specimen. All diagrams are lower hemispherical equal area stereonet projections contoured at $1 \%$ intervals. Contours for (a) are 1, 2, 3, 4 times uniform; for (b) through (d) they are 1, 2, 3, 4, 5, 6+ times uniform. The stereonets are oriented such that the foliation forms a vertical plane, while the observed lineation (and orientation of thin section) follows a horizontal E-W line. (a) Combined/bulk crystallographic fabric generated from an 8000-point grid mapped across the specimen. (b) Quartz crystallographic fabric generated from manually selected matrix grains. (c) Crystallographic fabric of the finer-sized quartz population within the quartz-rich lens. (d) Crystallographic fabric of the coarser-sized quartz population within the quartz-rich lens. inclined to the right, which is consistent with top-to-the-eastsoutheast shear.

The crystallographic fabric from the coarser grain-size population in the lens is similar to that from the finer-sized population; activation of the prism $\langle a\rangle$ and rhomb $\langle a\rangle$ slip systems dominates. Unlike the other intra-lens population, however, the fabric of the coarser-sized grains forms a type1 crossed-girdle (Fig. 4d). The main fabric displays a topto-the-right (or southeast) asymmetry, with weakly developed secondary arms extending away from the main girdle (Fig. 4d).

\subsection{Quartz crystallographic fabric interpretation}

With the exception of the prism $[c]$ slip (discussed below) the fabric asymmetries noted in the various specimen populations are consistent with interpreted top-to-the-east-southeast movement across the nearby Tirich Mir and Reshun faults (Fig. 1; Calkins et al., 1981; Hildebrand et al. 2001).

The quartz crystallographic fabric from the smaller grainsize population in the specimen analysed indicates a component of prism $[c]$ slip. Slip in the prism $[c]$ direction is typically associated with deformation in excess of $600-650^{\circ} \mathrm{C}$ (Lister and Dornsiepen, 1982; Mainprice et al., 1986; Morgan and Law, 2004). The rock sampled, however, is a lowmetamorphic-grade phyllite and has not experienced temperatures in the range of those expected to favour prism $[c]$ slip.

Similar unexpected patterns have been noted in lowmetamorphic-grade slates and phyllites in New Zealand where they are interpreted to reflect mechanical rotation of grains elongate in the $c$ axis direction parallel with the stretching direction (Stallard and Shelly, 1995). Such an interpretation is consistent with the sparse evidence of dynamic recrystallization in the matrix quartz. However, $c$ axis orientations consistent with slip in the rhomb and prism $\langle a\rangle$ directions indicate that there was some dynamic modification of the crystal lattice in response to deformation. As suggested by Stallard and Shelly (1995), physical rotation of the clasts may have occurred preferentially in the matrix grains surrounded by phyllosilicate-rich layers, into which strain was preferentially partitioned. The matrix quartz grains that occur in areas with less abundant phyllosilicate may have accommodated more of the strain directly through dislocation slip resulting in the development of the prism $\langle a\rangle$ and rhomb/basal $\langle a\rangle c$ axis orientations observed in the crystallographic fabric.

The development of quartz $c$ axis maxima parallel to the stretching lineation may alternatively be explained by preferential dissolution of quartz grains with their (0001) planes parallel to the foliation. The dissolution of such grains and re-precipitation and/or concentration of residual grains with $c$ axes parallel to the foliation have been interpreted to account for similar $c$ axis patterns in low-metamorphic-grade rocks in southeastern Brazil (Hippertt, 1994). 
The orientations of $c$ axes in grains that comprise the quartz-rich lens in the specimen appear to have been controlled by dynamic recrystallization (Fig. 3a-c) as part of their deformational response to imposed stresses. Because the quartz records evidence of dynamic recrystallization, the crystallographic fabrics measured from it are interpreted to reflect the modification of its crystal lattice orientation in response to deformation.

\subsection{Deformation temperature, grain-size piezometry, and strain rate estimates}

The crystallographic fabric from the coarser grains in the quartz lens forms a weakly developed crossed-girdle fabric (Fig. 4d). The opening angle of such fabrics, that is the angle between the arms of the fabric as measured about the perpendicular to the flow plane, has been empirically related to the estimated temperatures at which the fabrics developed (Kruhl, 1998; Morgan and Law, 2004; Law, 2014). Converting a fabric opening angle into a temperature of deformation requires a number of assumptions to be made, including temperature being the primary control on critically resolved shear stress, as opposed to strain rate or hydrolytic weakening. See Law (2014) for an in depth review of the considerations in using quartz crystallographic fabric opening angles as geothermometers. In reflection of the uncertainty in the data used for the empirical calibration and the precision of the opening angle determined, quartz crystallographic fabric-derived deformation temperatures are quoted at $\pm 50^{\circ} \mathrm{C}$ (Kruhl, 1998).

The crossed girdle fabric in the specimen analysed has an opening angle of $\sim 53^{\circ}$ (Fig. 4d), which corresponds to a deformation temperature of $\sim 403 \pm 50^{\circ} \mathrm{C}$. Although the $\mathrm{c}$ axis fabric is weakly developed, the temperature estimate is consistent with the interpreted metamorphic grade of the rock and with the observed microstructures, which are dominated by subgrain development with minor bulging. The transition from bulging to subgrain formation processes in the eastern Tonale fault zone of the Italian Alps is associated with temperatures near $400^{\circ} \mathrm{C}$ (Fig. 9 of Stipp et al., 2002). Similar textures from the Himalaya may occur at slightly higher temperatures, closer to $450^{\circ} \mathrm{C}$ (Law, 2014). It should be noted, however, that, as with $c$ axis opening angles, strain rate and hydrolytic weakening can also play an important role in the development of quartz textures (e.g. Law, 2014).

Recrystallized grain-size piezometry as proposed by Stipp and Tullis (2003) and recalibrated by Holyoke and Kronenburg (2010) may be used to estimate potential differences in differential flow stresses recorded in different dynamically recrystallized grain-size populations. Experimental calibration of the quartz grain-size piezometer applies to bulging recrystallization mechanisms and extends to a maximum grain size of $\sim 50 \mu \mathrm{m}$ (Stipp and Tullis, 2003; Stipp et al., 2006). Stipp et al. (2010) suggest that the piezometer may be reasonably applied to grains formed through subgrain rota-

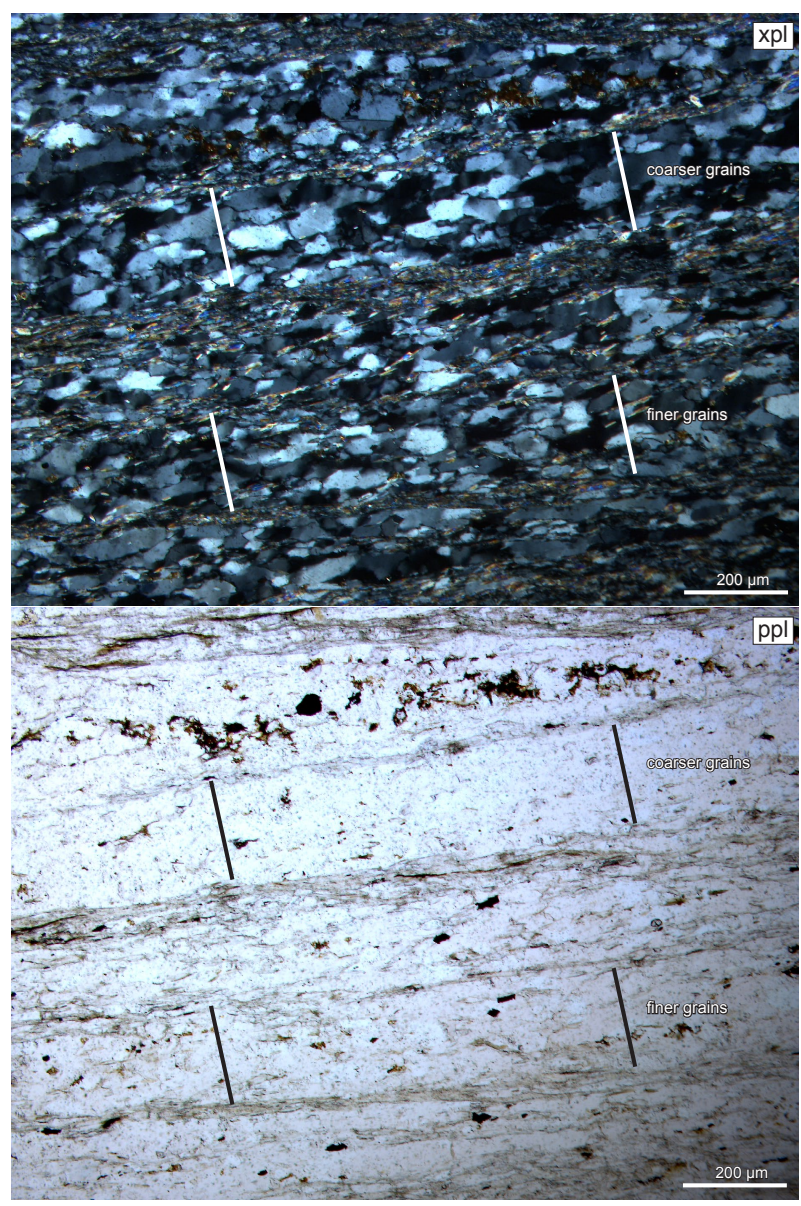

Figure 5. Cross-polarized (xpl) and plane polarized (ppl) photomicrographs of the quartz-rich lens analysed in specimen S32. Location of photomicrographs is shown in Fig. 2d. The coarser- and finer-size portions are approximately the same thickness and quartz grains in both do not appear to be significantly affected by pinning of phyllosilicate material.

tion recrystallization, but would significantly underestimate those developed during grain boundary migration recrystallization. Applying the quartz recrystallization piezometer to the two dynamically recrystallized grain-size populations in the quartz-rich lenses first requires assessment of potential secondary controls on grain size, such as pinning by phyllosilicates. Detailed examination of coarser and finer-grainsize regions within the quartz-rich lens (see location of detailed area in Fig. 2d) demonstrates that while there may be a minor increase in the amount of phyllosilicate associated with the finer-grain-size region it does not control the size of the quartz grains (Fig. 5). If dynamic recrystallization is considered to be the primary control on grain size in the quartz-rich lens then calculations based on the Holyoke and Kronenburg (2010) calibration of the Stipp and Tullis (2003) piezometer indicate differential stresses of $8.6+2.6 /-1.5$ and $15.0+3.8 /-2.5 \mathrm{MPa}$ for the coarser and finer quartz grain-size populations, respectively. 

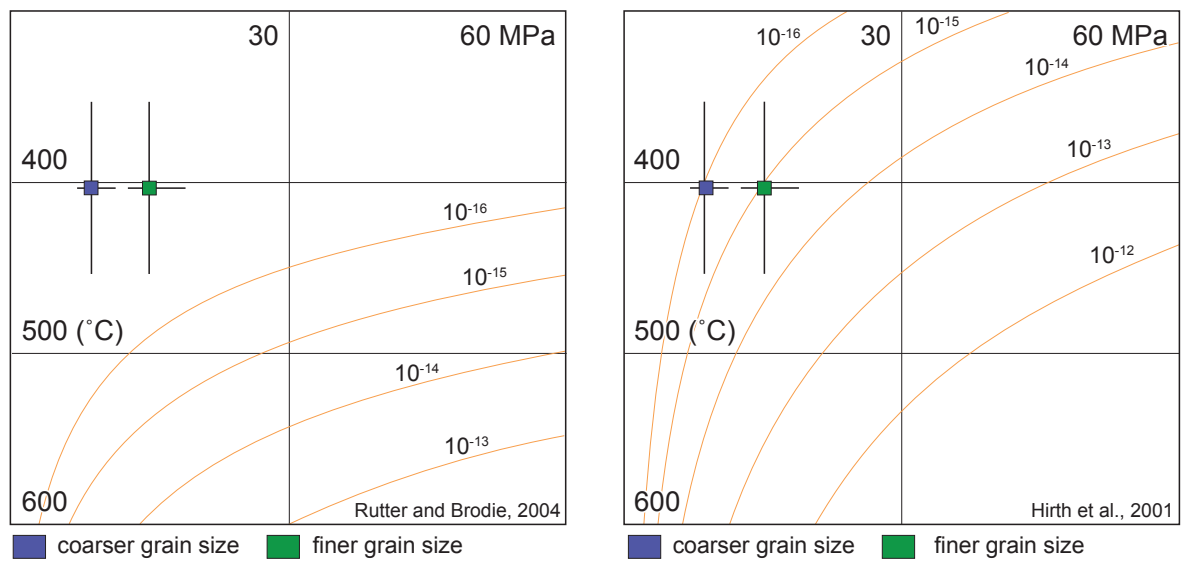

Figure 6. Strain rate estimates for the two size-populations within the quartz-rich lenses using the flow laws of Hirth et al. (2001) and Rutter and Brodie (2004). Differential stress estimates are from recrystallized grain-size piezometry while temperature estimates are from quartz crystallographic fabric opening angles. See text for discussion.

The differential stress estimates determined can be combined with deformation temperature and plotted atop a series of different geologically reasonable strain rates (Fig. 6). As pressure constraints have not been established for the specimen S32 or any relevant nearby locales, the fugacity used in both the Hirth et al. (2001) and Rutter and Brodie (2004) quartz flow law calibrations utilized was estimated using the derived deformation temperature, a thermal gradient of $25^{\circ} \mathrm{C} \mathrm{km}^{1}$, and an average crustal density of $2.85 \mathrm{~g} \mathrm{~cm}^{-3}$. The resulting fugacity, $108 \mathrm{MPa}$, was calculated as in Pitzer and Sterner (1994). As noted in Law et al. (2013), calculated strain rates are rather insensitive to changes in fugacity; using a thermal gradient of $40^{\circ} \mathrm{C} \mathrm{km}^{1}$ in fugacity calculations does not result in a significant change in the strain rate estimates for this study. Plotted differential stresses and deformation temperature indicates a faster strain rate for the finer grains/higher differential stress (Fig. 6). The strain rate estimates vary considerably between the two calibrations with only the Hirth et al. (2001) calibration providing estimates that approach those geologically reasonable (Fig. 6).

\section{Discussion}

The size variation between the matrix and lens quartz grains in the specimen may reflect primary differences associated with the protolith. The finer-sized quartz grains found within the phyllitic matrix are interpreted to represent smaller grains deposited within a silt-/mud-dominated protolith, while the coarser quartz that occurs within the specimen is interpreted to represent a thin sand lens. Within the lens itself, the two grain-size populations may reflect further primary differences, secondary modification during deformation, or both. These possibilities are discussed below.

It is possible that the two grain-size populations within the lens reflect different strain histories. The quartz within the lens has been subject to dynamic recrystallization during which there would have been potential for the grains to change size and shape. The grain-size difference within the lens may reflect development of the finer population where stress was preferentially partitioned resulting in more intense grain-size reduction, whereas the courser population, affected by lower stresses, may reflect more limited grainsize reduction. Such stress partitioning is consistent with differential stress estimates made based on grain-size piezometry that indicated higher stresses associated with smaller grain sizes.

The two grain sizes may, alternatively (or additionally), reflect an initial difference in grain size inherited from the sand lens when it was first deposited, perhaps compounded by incomplete recrystallization of the larger grains. The variation in grain size within the quartz-rich lens may represent a combination of both primary differences and secondary strain partitioning. Finer grains within the quartz lens may have been preferred for initial strain partitioning, which would have facilitated, and been enhanced by, further grainsize reduction and higher strain rates. Strain concentration within the finer grains in the quartz-rich lens is consistent with the variation in crystallographic fabrics between the two size populations. The coarser-grain-size fabric maintains secondary trailing arms (Fig. 4d), whereas in the finer-grain-size fabric, those arms have been essentially obliterated (Fig. 4c). Migration towards a single girdle fabric has been associated with increased critically resolved shear stress and shear strain (Keller and Stipp, 2011) in quartz crystallographic fabric evolution models. 


\section{Conclusions}

This study demonstrates the importance of spatial resolution and registration in specimens analysed for crystallographic fabric analyses. In this metapelite example, the bulk crystallographic fabric overwhelmed two spatially restricted fabrics recorded in a quartz lens. Yet it was the secondary, spatially distinct fabrics that yielded information on deformation temperature, paleopiezometry, and strain rate. This has important implications for increasingly common studies that examine large numbers of specimens utilizing automated methods; care must be taken to investigate the spatial distribution of fabric symmetry within specimens as the bulk pattern may average and mask important information. The spatially controlled crystallographic fabric patterns documented in this study may reflect the fundamental initial properties of the specimen, byproducts of differential strain partitioning at the microscale, or some combination of the two.

Acknowledgements. This project was supported by NSERC Discovery and CFI Leaders Opportunity Fund grants to K. Larson. A. Khan and the NCEG at the University of Peshawar are thanked for their logistical assistance during fieldwork. Discussions with D. Kellett, reviews by C. Wilson and N. Mancktelow, and editorial handling and initial review by $\mathrm{R}$. Law have helped improve the clarity of the manuscript.

Edited by: R. Law

\section{References}

Blumenfeld, P., Mainprice, D., and Bouchez, J.-L.: $C$-slip in quartz from subsolidus deformed granite, Tectonophysics, 127, 97-115, 1986.

Bouchez, J.-L. and Pêcher, A.: Plasticite du quartz et sens de cisaillement dans des quartzites du Grand Chevaughement Central himalayen, Bulletin du societie geologique, France, 7, 13771385, 1976.

Calkins, J. A., Jamiluddin, S., Bhuyan, K., and Hussain, A.: Geology and Mineral Resources of the Chitral-Parstan Area, Hindu Kush Range, Northern Pakistan. Geological Survey (USA) Professional Paper 716-G, 1981.

Debon, F., Afzali, H., LeFort, P., and Sonet, J.: Major intrusive stages in Afghanistan: typology, age, and geodynamic setting, Geologische Rundschau, 76, 245-264, 1987.

Desio, A.: On the geological age of some granites of the Karakoram, Hindu Kush and Badakhshan (central Asia), in: Proceeding of the 22nd International Geological Congress, Delhi, Part II, 11, 479496, 1964.

Faisal, S., Larson, K. P., Cottle, J. M., and Lamming, J.: Building the Hindu Kush: Monazite Records of Terrane Accretion, Plutonism, and the Evolution of the Himalaya-Karakoram-Tibet Orogen, Terra Nova, 26, 395-401, 2014.

Feuten, F. and Goodchild, J. S.: Quartz $c$ axes orientation determination using the rotating polarizer microscope, J. Struct. Geol., 23, 896-902, 2001.
Gaetani, M., Le Fort, P., Tanoli, S., Angiolini, L., Nicora, A., Sciunnach, D., and Asif, K.: Reconnaissance geology in Chitral, Baroghil and Karambar districts (N Pakistan), Geol. Rundsch., 85, 683-704, 1996.

Heilbronner, R. P. and Pauli, C.: Integrated spatial and orientation analysis of quartz $c$ axes by computer-aided microscopy, J. Struct. Geol., 15, 369-382, 1993.

Heuberger, S., Schaltegger, U., Burgi, J.P., RG1, Villa, I.M., Frank, M., Dawood, H., Hussain, S., and Zanchi, A.: Age and isotopic constraints on magmatism along the Karakoram-Kohistan Suture Zone, NW Pakistan: evidence for subduction and continued convergence after India-Asia collision, Swiss J. Geosci., 100, 85107, 2007.

Hildebrand, P. R., Noble, S. R., Searle, M. P., Parrish, R. R., and Shakirullah: Tectonic significance of $24 \mathrm{Ma}$ crustal melting in the eastern Hindu Kush, Pakistan, Geology, 26, 871-874, 1998.

Hildebrand, P. R., Searle, M. P., Shakirullah, Khan, Z., and Van Heijst, H.: Geological evolution of the Hindu Kush, NW Frontier Pakistan: active margin to continent-continent collision zone, Geol. Soc. London Spec. Publicat., 170, 277-293, 2000.

Hildebrand, P. R., Noble, S. R., Searle, M. P., Waters, D. J., and Parrish, R. R.: Old origin for an active mountain range: Geology and geochronology of the eastern Hindu Kush, Pakistan, Geol. Soc. Am. Bull., 113, 625-639, 2001.

Hippertt, J. F.: Microstructures and $c$ axis fabrics indicative of quartz dissolution in sheared quartzites and phyllonites, Tectonophysics, 229, 141-163, 1994.

Hirth, G. and Tullis, J.: Dislocation creep regimes in quartz aggregates, J. Struct. Geol., 14, 145-160, 1992.

Hirth, G., Teyssier, C., and Dunlap, J.: An evaluation of quartzite flow laws based on comparisons between experimentally and naturally deformed rocks, Internat. J. Earth Sci., 90, 77-87, 2001.

Holyoke III, C. W. and Kronenberg, A. K.: Accurate differential stress measurement using the molten salt cell and solid salt assemblies in the Griggs apparatus with applications to strength, piezometers and rheology, Tectonophysics, 494, 17-31, 2010.

Keller, L. M. and Stipp, M.: The single-slip hypothesis revisited: Crystal-preferred orientations of sheared quartz aggregates with increasing strain in nature and numerical simulation, J. Struct. Geol., 33, 1491-1500, 2011.

Kile, D. E.: The universal stage: The past, present, and future of a mineralogical research instrument, Geochemical News, p. 140, 2009.

Kruhl, J. H.: Reply: Prism- and basal plane parallel subgrain boundaries in quartz: a microstructural geothermobarometer, J. Metamor. Geol., 16, 142-146, 1998.

Larson, K. P. and Cottle, J. M.: Midcrustal discontinuities and the assembly of the Himalayan midcrust, Tectonics, 33, doi:10.1002/(ISSN)1944-9194, 2014.

Law, R. D.: Deformation thermometry based on quartz $c$ axis fabrics and recrystallization microstructures: A review, J. Struct. Geol., 66, 129-161, 2014.

Law, R. D., Schmid, S., and Wheeler, J.: Simple Shear Deformation and Quartz Crystallographic Fabrics - a Possible Natural Example From the Torridon Area of Nw Scotland, J. Struct. Geol., 12, 29-45, 1990.

Law, R. D., Searle, M. P., and Simpson, R. L.: Strain, deformation temperatures and vorticity of flow at the top of the Greater 
Himalayan Slab, Everest Massif, Tibet, J. Geol. Soc., 161, 305320, 2004.

Law, R. D., Mainprice, D., Casey, M., Lloyd, G., Knipe, R., Cook, B., and Thigpen, J.: Moine Thrust zone mylonites at the Stack of Glencoul: I-microstructures, strain and influence of recrystallization on quartz crystal fabric development, Geol. Soc. London Spec. Publicat., 335, 543 pp., 2010.

Law, R. D., Jessup, M. J., Searle, M. P., Francsis, M. K., Waters, D. J., and Cottle, J. M.: Telescoping of isotherms beneath the South Tibetan Detachment System, Mount Everest Massif, J. Struct. Geol., 33, 1-26, 2011.

Law, R. D., Stahr, D. W., Francsis, M. K., Ashley, K. T., Grasemann, B., and Ahmad, T.: Deformation temperatures and flow vorticities near the base of the Greater Himalayan Series, Sutlej Valley and Shimla Klippe, NW India, J. Struct. Geol., 54, 1-93, 2013.

Lister, G. S. and Dornsiepen, U. F.: Fabric transitions in the Saxony granulite terrain, J. Struct. Geol., 4, 81-92, 1982.

Lister, G. S. and Williams, P. F.: Fabric development in shear zones: theoretical controls and observed phenomena, J. Struct. Geol., 1, 283-297, 1979.

Mainprice, D. Bouchez, J. L., Blumenfeld, P., and Tubia, J. M: Dominant $c$ slip in naturally deformed quartz: implications for dramatic plastic softening at high temperature, Geology, 14, 819$822,1986$.

Morgan, S. S. and Law, R. D.: Unusual transition in quartzite dislocation creep regimes and crystal slip systems in the aureole of the Eureka Valley-Joshua Flat-Beer Creek pluton, California: a case for anhydrous conditions created by decarbonation reactions, Tectonophysics, 384, 209-231, 2004.

Pajdzik, L. A. and Glazer, A. M.: Three-dimensional birefringence imaging with a microscope tilting-stage. I. Uniaxial Crystals, J. Appl. Crystall., 39, 326-337, 2006.

Peternell, M., Hasalová, P., Wilson, C. J. L., Piazolo, S., and Schulmann, K.: Evaluating quartz crystallographic preferred orientations and the role of deformation partitioning using EBSD and fabric analyser techniques, J. Struct. Geol., 32, 803-817, 2010.

Pitzer, K. S. and Sterner, S. M.: Equations of state valid continuously from zero to extreme pressures for $\mathrm{H}_{2} \mathrm{O}$ and $\mathrm{CO}_{2}$, J. Chem. Phys., 101, 3111-3116, 1994.

Prior, D. J., Boyle, A. P., Brenker, F., Cheadle, M. C., Day, A., Lopez, G., Peruzzo, L., Potts, G. J., Reddy, S., Speiss, R., Timms, N. E., Trimby, P., Wheeler, J., and Zetterström, L.: The application of electron backscatter diffraction and orientation contrast imaging in the SEM to textural problems in rocks, Am. Mineral., 84, 1741-1759, 1999.

Rutter, E. and Brodie, K.: Experimental intracrystalline plastic flow in hot-pressed synthetic quartzite prepared from Brazilian quartz crystals, J. Struct. Geol., 26, 259-270, 2004.

Sander, B.: Einführung in die Gefügekunde der Geologischen Körper, Zweiter Teil, Die Korngefuege, Springer-Verlag, WeinInssbruck, 1950.

Schmid, S. M. and Casey, M.: Complete fabric analysis of some commonly observed quartz $[c]$ axis patterns. In: Hobbs, B.E., Heard, H.C. (Eds.), Mineral and Rock Deformation: Laboratory Studies, Geophys. Monogr., 36, 263-286, 1986.
Stallard, A. and Shelly, D.: Quartz c-axes parallel to stretching directions in very low-grade metamorphic rocks, Tectonophysics, 249, 31-40, 1995.

Stipp, M. and Tullis, J.: The recrystallized grain size piezometer for quartz, Geophys. Res. Lett., 30, 2088, doi:10.1029/2003GL018444, 2003.

Stipp, M., Stunitz, H., Heilbronner, R., and Schmid, S. M.: The eastern Tonale fault zone: a natural laboratory for crystal plastic deformation of quartz over a temperature range from 250 to $700{ }^{\circ} \mathrm{C}$, J. Struct. Geol., 24, 1861-1884, 2002.

Stipp, M., Tullis, J., and Behrens, H.: Effect of water on the dislocation creep microstructure and flow stress of quartz and implications for the recrystallized grain size piezometer, J. Geophys. Res., 111, B042201, doi:10.1029/2005JB003852, 2006.

Stipp, M., Tullis, J., Scherwath, M., and Behrmann, J. H.: A new perspective on paleopiezometry: Dynamically recrystallized grain size distributions indicate mechanism changes, Geology, 38, 759-762, 2010.

Turner, F. J.: Preferred orientation of olivine crystals in peridotite, Trans. Proc. Roy. Soc. New Zealand, 72, 280-300, 1942

Wenk, H.-R. (Ed.): Preferred Orientaiton in Deformed Metals and Rocks: An introduction to Modern Texture Analysis. Academic Press, London, p. 610, 1985.

Wilson, C. J. L., Russell-Head, D. S., and Sim, H. M.: The application of an automated fabric analyser system to the textural evolution of folded ice layers in shear zones, Ann. Glaciol., 37, 7-17, 2003.

Wilson, C. J. L., Russell-Head, D. S., Kunze, K., and Viola, G.: The analysis of quartz c-axis fabrics using a modified optical microscope, J. Micros., 227, 30-41, 2007.

Wilson, C. J. L., Robinson, J., and Dugdale, A.: Quartz vein fabrics coupled to elevated fluid pressures in the Stawell gold deposit, south-eastern Australia, Mineral. Deposita, 44, 245-263, 2009.

Wilson, C. J. L. and Peternell, M. A.: Evaluating ice fabrics using fabric analyser techniques in Sørsdal Glacier, East Antarctica, J. Glaciol., 57, 881-894, 2011.

Xypolias, P. and Koukouvelas, I. K.: Kinematic vorticity and strain rate patterns associated with ductile extrusion in the Chelmos Shear Zone (External Hellenides, Greece), Tectonophysics, 338, 59-77, 2001.

Zanchi, A. and Gaetani, M.: The geology of the Karakoram range, Pakistan: the new $1: 100000$ geological map of Central-Western Karakoram. Italian J. Geosci., 130, 161-262, 2011.

Zanchi, A., Poli, S., Fumagalli, P., and Gaetani, M.: Mantle exhumation along the Tirich Mir Fault Zone, NW Pakistan: premid-Cretaceous accretion of the Karakoram terrane to the Asian margin, in: Tectonics of the Nanga Parbat Syntaxis and the Western Himalaya, edited by: Khan, M. A., Treloar, P. J., Searle, M. P., and Jan, M. Q., Geol. Soc. London, Special. Publication, 170, 237-252, 2000.

Zhang, S. and Karato, S. I.: Lattice preferred orientation of olivine aggregates deformed in simple shear, Nature, 375, 774-777, 1995. 